\title{
Severe glyphosate - surfactant herbicide poisoning; successful treatment - case report
}

\begin{abstract}
Glyphosate-surfactant herbicide is one of the most frequently used herbicides. When large volumes of concentrates are ingested intentionally, it can generate fatal symptoms that are refractory to treatment. We present a case of a 45 -year-old male who suffered from psychosis and deliberately drank a $1 / 2$-liter of glyphosate-surfactant herbicide. His consciousness deteriorated into a coma, and he developed ARDS. Cardiovascular collapse developed. Acute renal failure, hyperkalemia and metabolic acidosis also developed. He was admitted to the intensive care unit. Orotracheal intubation was performed and mechanical ventilation was initiated. Infusions of dopamine and norepinephrine were also started. Continuous veno-venous hemodiafiltration was started 11 hours after ingestion and was performed for 5 days. Intermittent daily two-hour dialysis was performed for further 18 days. His renal function had fully recovered. He was mechanically ventilated for 9 days. After treatment, he was discharged to go home fully recovered with no neurological deficits. This is a case of severe glyphosate-surfactant herbicide poisoning which was successfully cured by supportive treatment and CVVHDF. According to the literature this is among the largest ingestion that patient survived.
\end{abstract}

Keywords: cardiovascular collapse, anuric acute renal failure, altered consciousness, severe poisoning, supportive treatment
Volume 4 Issue I - 2017

\author{
Zeljko Nincevic,' Jasna Nincevic, ${ }^{2}$ Maja \\ Gabelica, ${ }^{3}$ Zeljko Sundov, ${ }^{4}$ Zeljko Puljiz, ${ }^{4}$ \\ Mirko Gabelica ${ }^{5}$ \\ 'Department of Anaesthesiology and Intensive Care Medicine, \\ University Hospital Split, Croatia \\ ${ }^{2}$ Department of Epidemiology, Public Health Institute of Split \\ and Dalmatian County, Croatia \\ ${ }^{3}$ Department of Emergency Medicine of Split and Dalmatian \\ County, Croatia \\ ${ }^{4}$ Department of Internal Medicine, University Hospital Split, \\ Croatia \\ ${ }^{5}$ Department of Ear, nose and throat, University Hospital Split, \\ Croatia
}

\begin{abstract}
Correspondence: Zeljko Nincevic, Department of Anaesthesiology and Intensive Care Medicine, University Hospital Split, Spinciceva I21000 Split, Croatia,Tel 0038521556|84,Email zeljko.nincevic@gmail.com
\end{abstract}

Received: August 23, 2017| Published: September II, 2017
Abbreviations: ECG, electrocardiography; CVVHDF, continuous veno-venous hemo dia filtration; ARDS, acute respiratory distress syndrome

\section{Introduction}

Glyphosate-surfactant herbicide is one of the most frequently used herbicides. Glyphosate kills plants by suppressing the shikimic metabolic pathway. ${ }^{1}$ The mechanism of toxicity of glyphosate in mammals has been proposed to be the uncoupling of oxidative phosphorylation. ${ }^{2}$ Surfactants are inert ingredients that are added to herbicides to precisely increase the absorption of the active component. Surfactants may contribute to the toxicity of the active substance. ${ }^{1}$ An experiment in dogs found that hypotension is primarily caused by myocardial depression with surfactant. ${ }^{3}$ The ingestion of small amounts of glyphosate-surfactant herbicide usually causes only mild symptoms. However, when large volumes of concentrates are ingested intentionally, it can generate potentially fatal symptoms that are refractory to the treatment. ${ }^{4}$ The treatment for glyphosatesurfactant herbicide poisoning is primarily of a supportive nature. ${ }^{5}$ Early continuous veno-venous hemodiafiltration (CVVHDF) contributes to the survival. ${ }^{4,6}$

\section{Case report}

At noon, a 45-year-old man deliberately drank a $1 \frac{1}{2}$-liter of glyphosate-surfactant herbicide (trade name Cidokor). Cidokor is formulated as a liquid concentrate for solution and contains $480 \mathrm{~g} /$ $\mathrm{L} \pm 24 \mathrm{~g} / \mathrm{L}$ (41.5\% approx. weight) monoizopropylamine glyphosate salt (monoizopropylamine salt of N-phosphonomethyl-glycine). Other ingredients include ethoxylated fatty amines (mixture of n-alkyl $\left(\mathrm{C}_{14}+\mathrm{C}_{16}+\mathrm{C}_{18}\right)-\mathrm{N}, \mathrm{N}$, -bis (poliethoxylated) fatty amines $176 \mathrm{~g} / \mathrm{L} \pm 11 \mathrm{~g} / \mathrm{L}$ ( $15.5 \%$ approx. weight). Cidokor is manufactured by Monsanto Europe SA, Brussels, Belgium. Immediately after drinking the poison, his wife gave him a few deciliters of milk to drink. For many years, the patient had suffered from psychosis, which was recently in a deterioration (paroxetine and risperidone were not taken regularly). He consumed alcohol. After poisoning he was transported by boat from the island to the hospital. He was admitted into the Gastroenterology Department at 3 p.m. Upon admission, he was conscious, complained of pain in the throat and epigastric area. Treatment was started, and diuresis was stimulated by furosemide. Hyperkalemia was corrected with an infusion of glucose and insulin, sodium bicarbonate and calcium gluconate. The patient received pantoprazole, amiodarone and oxygenation through a facemask with a bag. Despite treatment, his consciousness deteriorated into a coma (Glasgow coma score 3), and the patient demonstrated dilated pupils and no reaction to light. Chest X-rays showed confluent opacities and the development of ARDS. Cardiovascular collapse developed (blood pressure $80 / 50 \mathrm{mmHg}$ ). Anuric acute renal failure, hyperkalemia and metabolic acidosis also developed. ECG showed progressive hyperkalemia. Nasogastric retention of bloody content was large. Rhabdomyolysis developed. For further treatment, he was admitted to the intensive care unit. Orotracheal intubation was performed, and mechanical ventilation was started. A central venous catheter and arterial line were placed for invasive hemodynamic monitoring. Saline infusion, infusions of dopamine $(15 \mu \mathrm{g} / \mathrm{kg} / \mathrm{min})$ and norepinephrine $(0.25 \mu \mathrm{g} / \mathrm{kg} / \mathrm{min})$ were started as inotropic and vasoactive support. Hydrocortisone $(1.5 \mathrm{~g})$, vitamin $\mathrm{B}_{1}(250 \mathrm{mg})$, continuous infusion of bicarbonates $(250 \mathrm{mmol})$ and antibiotic ceftrixone were administered. CVVHDF was started at 11 p.m. Laboratory findings before and three days after the start of CVVHDF are presented in Table 1. In our case, for vascular access, a double lumen catheter was inserted percutaneously into the right subclavian vein. A prisma $\mathrm{M}_{100}$ preset was used. The manufacturer of the device was Gambro Industries, 
Meyzieu Cedex, France. The Gambro Prismaflex system hemofilter $\mathrm{M}_{100}$ set with the acrylonitrile $\left(\mathrm{AN}_{69}\right)$ membrane was used. Four hours after the initiation of CVVHDF, the patient spontaneously opened his eyes. Electrolyte and acid-base disorders were gradually normalized. He was mechanically ventilated for 9 days. Chest X-rays showed complete regression of confluent opacities. The infusion of norepinephrine and dopamine was terminated after 5 days and 8 days, respectively. CVVHDF was performed for 5 days. Intermittent daily two-hour dialysis was further performed. Spontaneous urine output occurred on the ninth day, and gradually increased. The patient was dialyzed for 18 days. We fed the patient parenterally for 9 days, after which, we than gradually introduced enteral nutrition. Treatment was continued at the nephrology and psychiatric clinics. After 50 days of treatment the patient was discharged to home treatment fully recovered with no neurological deficits. His renal function was fully recovered.

Table I Laboratory findings before and three days after the start of CVVHDF

\begin{tabular}{|c|c|c|}
\hline & $\begin{array}{l}\text { Ist }^{\text {st }} \text { Day (Before } \\
\text { CVVHDF) }\end{array}$ & $3^{\text {rd }}$ Day \\
\hline Leukocytes (xI09/L) & 41 & 10.1 \\
\hline Erythrocytes (x1012/L) & 5.7 & 4.6 \\
\hline Hemoglobin (g/L) & 174 & 140 \\
\hline INR & 1.01 & 1.12 \\
\hline apTT (sec) & 24 & 46 \\
\hline Pletelets (x109/L) & 420 & 172 \\
\hline Blood Glucose (mmol/L) & 7.6 & 9.1 \\
\hline Urea (mmol/L) & 9 & 12.3 \\
\hline Creatinine $(\mu \mathrm{mol} / \mathrm{L})$ & 195 & 282 \\
\hline $\begin{array}{l}\text { Creatinine Phosphokinase } \\
\text { (U/L) }\end{array}$ & 114 & 2038 \\
\hline Myoglobin ( $\mu g / L)$ & 564.6 & 4085 \\
\hline Sodium (mmol/L) & 142 & 132 \\
\hline Potassium (mmol/L) & 7.8 & 3.9 \\
\hline Total Bilirubin $(\mu \mathrm{mol} / \mathrm{L})$ & 8.1 & 22.2 \\
\hline AST (U/L) & 68 & 120 \\
\hline ALT (U/L) & 38 & 59 \\
\hline GGT (U/L) & 53 & 105 \\
\hline Lactate Dehydrogenase (U/L) & 377 & 436 \\
\hline Sat $\mathrm{aO}_{2}(\%)$ & 67 & 95 \\
\hline $\mathrm{pH}$ & 7.06 & 7.39 \\
\hline Base Excess (mmol/L) & -17.8 & I \\
\hline Lactate $(\mathrm{mmol} / \mathrm{L})$ & 4.8 & 1.2 \\
\hline
\end{tabular}

\section{Discussion}

In the case of glyphosate-surfactant herbicide poisoning pulmonary edema, abnormal chest $\mathrm{x}$-ray, respiratory distress necessitating intubation, shock (systolic blood pressure less than $90 \mathrm{mmHg}$ ), altered consciousness, renal failure necessitating hemodialysis, larger amount of ingestion $(>200 \mathrm{~mL})$, and hyperkalemia are predictors that are highly associated with poor outcomes and mortality., 5 There is a significant correlation between the amount of ingested glyphosate-surfactant herbicide and the probability of severe systemic consequences or death. Ingestion of more than $85 \mathrm{~mL}$ of concentrated preparation will cause serious signs of poisoning in adults. ${ }^{8}$ Sawada et al. ${ }^{9}$ reported that the amount of Roundup ingested by patient who died was 206mL. ${ }^{9}$ Tominack ${ }^{10}$ and colleagues examined 97 cases of glyphosate-surfactant herbicide ingestion and showed that the average amount ingested by survivors was $120 \pm 112 \mathrm{~mL}$ and by nonsurvivors was $263 \pm 100 \mathrm{~mL} .{ }^{10}$ The estimated amount of glyphosate-surfactant herbicide ingested by the patients who died in the study of Lee and colleagues was $330 \pm 42 \mathrm{~mL} .{ }^{5}$ According to the literature this is among largest ingestion of poison that patient survived. The treatment for glyphosate surfactant poisoning is primarily of a supportive nature. ${ }^{5}$ Early hemodialysis and continuous veno-venous hemodiafiltration contributes to the survival of patients because significant amounts of glyphosate are primarily excreted in urine. ${ }^{2} \mathrm{Moon}^{4}$ and colleagues reported two patients who intentionally ingested glyphosatesurfactant herbicide $(300 \mathrm{~mL}$ and $200 \mathrm{~mL}$, respectively), and both patients exhibited cardiovascular collapse and complicated renal failure, despite the use of aggressive supportive therapy. Hemodialysis was performed, and the results were satisfactory. This was the first report in the literature about a full recovery in patients following the application of hemodialysis in unstable patients after glyphosateherbicide poisoning. ${ }^{4}$ Garlich $^{6}$ and colleagues reported a 62 -yearold male who drank a bottle of commercial glyphosate-surfactant herbicide. Despite aggressive treatment, he developed acidosis and hyperkalemia, and 16 hours after ingestion, hemodialysis was started. After hemodialysis, his clinical status had improved. They showed that hemodialysis had successfully removed $91.8 \%$ of the glyphosate. ${ }^{6}$ Knezevic ${ }^{11}$ and colleagues described a case of a 36-year-old patient who had suicidally ingested $300 \mathrm{~mL}$ gyphosate-surfactant herbicide and developed acidosis, hyperkalemia, hypotension, hypoxia and acute oliguric renal failure. They treated him with postdilution CVVHDF over 27.5 hours. The patient survived. ${ }^{11}$ Mahendrakar ${ }^{12}$ and colleagues presented a case report of a 35-year-old man who intentionally drank $200 \mathrm{~mL}$ of glyphosate-surfactant herbicide. After 6 hours, CVVHDF was started because he had developed severe acidosis, hyperkalemia and high creatinine. The patient was successfully treated and discharged after 18 days. ${ }^{12}$ Lee and colleagues presented a case of a 60-year-old patient who, after ingestion of glyphosate-surfactant herbicide developed serious pulmonary edema, severe metabolic acidosis (pH-6.96) and hyperkalemia ( $\mathrm{K} 8.8)$. He was in cardiac arrest. After the administration of CVVHDF, metabolic acidosis and hyperkalemia improved, and his vital signs stabilized. He was successfully recovered. ${ }^{13}$

\section{Conclusion}

The treatment for glyphosate -surfactant herbicide poisoning is primarily of a supportive nature. Early initiation of renal replacement therapy contribute to the survival. Sampogna \& Cunard ${ }^{14}$ advise early initiation of renal replacement therapy when a large quantity of poison is ingested $(>200 \mathrm{~mL}){ }^{14}$

\section{Acknowledgements}

None. 


\section{Conflict of interest statement}

The authors report no conflicts of interest. The authors alone are responsible for the content and writing of this manuscript.

\section{References}

1. Gary L Diamond, Patrick R Durkin. Effects of Surfactants on the Toxicity of Glyphosate, with Specific Reference to RODEO. New York: Syracuse Environmental Research Associates; 1997. p. 1-28.

2. Bates N, Campbell A. Glyphosate. In: Campbell A, editor. Handbook of Poisoning in Dogs and Cats. 1st ed. Blackwell Science Ltd, England, UK; 2000. p. 135-138.

3. Tai T, Yamashita M, Wakimori H. Hemodynamic effects of roundup, glyphosate and surfactant in dogs. Jpn J Toxicol. 1990;3:63-68.

4. Moon JM, Min Y, Chun BJ. Can early hemodyilysis affect the outcome of the ingestion of glyphosate herbicide? Clin Toxicol (Phila). 2006;44(3):329-332.

5. Lee HL, Chen KW, Chi CH, et al. Clinical presentations and prognostic factors of a glyphosate-surfactant herbicide intoxication: a review of 131 cases. Acad Emerg Med. 2000;7(8):906-910.

6. Garlich F, Goldman M, Pepe J, et al. Hemodialysis clearance of glyphosate following a life-threatening ingestion of glyphosate-surfactant herbicide. Clin Toxicol (Phila). 2014;52(1):66-71.
7. Lee AH, Shin CP, Hsu KH, et al. The early prognostic factors of glyphosate-surfactant intoxication. Am J Emerg Med. 2008;26(3):275-281.

8. Bradberry SM, Proudsfoot AT, Vale JA. Glyposhate poisoning. Toxicol Rev. 2004;23(3):159-167.

9. Sawada Y, Nagai Y, Ueyama M, et al. Probable toxicity of surface-active agent in commercial herbicide containing glyphosate. Lancet. 1988;1(8580):299.

10. Tominack RL, Yang GY, Tsai WJ, et al. Taiwan National Poisoning Center survey of glyphosate surfactant herbicide ingestion. J Toxicol Clin Toxicol. 1991;29(1):91-109.

11. Knežević V, Božić D, Budošan I, et al. Early continuous dialysis in acute glyphosate-surfactant poisoning. Srp Arh Celok Lek. 2012;140(910):648-652.

12. Mahendrakar K, Venkategowda PM, Rao SM, et al. Glyphosate surfactant herbicide poisoning and management. Indian J Crit Care Med. 2014;18(5):328-330.

13. Lee BK, Lee HY, Ryu HH, et al. Continuous renal replacement therapy in a patient with cardiac arrest after glyphosate-surfactant herbicide poisoning. Hong Kong J Emerg Med. 2012;19(3):214-217.

14. Sampogna RV, Cunard R. Roundup intoxication and a rationale for treatment. Clin Nephrol. 2007;68(3):190-196. 